\title{
Percutaneous Full Endoscopic Ligamentum Flavum Splitting Interlaminar Approach for Removal of Dorsally Migrated Lumbar Disc Herniation: A case Report with Technical Note
}

\author{
Hyeun Sung Kim², Byapak Paudel ${ }^{1}$, Jee Soo Jang ${ }^{1}$, Seong Hoon $\mathrm{Oh}^{2}$, Il-Tae Jang ${ }^{3}$ \\ ${ }^{1}$ Department of Neurosurgery, Nanoori Suwon Hospital, Suwon, \\ ${ }^{2}$ Department of Neurosurgery, Nanoori Incheon Hospital, Incheon, \\ ${ }^{3}$ Department of Neurosurgery, Nanoori Hospital, Seoul, Korea
}

Corresponding Author: Byapak Paudel, MD, MS, Fellowship in Spine Surgery Department of Neurosurgery, Nanoori Suwon Hospital, 295 , Jungbu-daero, Yeongtong-gu, Suwon, Korea

Tel: $+82-31-1688-9797$ Fax: +82-31-8065-9701

E-mail: drbyapak@gmail.com

Received: December 8, 2016 Revised: March 13, 2017 Accepted: March 22, 2017

\begin{abstract}
Treatment of dorsally migrated lumbar disc described so far commonly in present literature is removal by open technique through hemi or complete laminectomy or by use of microsurgical technique or by partial use of endoscope without use of irrigation system. We present a case of dorsally migrated disc herniation treated safely with good outcome by Percutaneous Full Endoscopic Ligamentum Flavum Splitting Interlaminar Approach. A 60 years old man presented with subacute onset of back pain and right leg radiating pain with weakness of right great toe dorsiflexion and diagnosed as a case of dorsally migrated L4-5 disc herniation was treated with this technique. He had also subtle instability at that level. His pain resolved immediately after surgery. Weakness of right great toe also resolved gradually in 2 months. Postoperative X-ray showed no further instability. Postoperative MRI revealed complete removal of disc with resolution of cauda equina compression. No complication was noted related to this technique. This new technique ultimately preserves motion segment while simultaneously addressing symptomatic pathology of dorsally migrated HNP with added benefits of minimally invasive spine surgery.
\end{abstract}

Key Words: Dorsally migrated lumbar disc herniation, Ligamentum flavum splitting interlaminar approach, Percutaneous full endoscopic removal, Subtle instability

\section{INTRODUCTION}

In 1973, Lombardi first reported a case of posterior epidural migration of a lumbar disc fragment and described the lesion as a "posterior rotation of annulus fibrosus"13). However, Lichtor has claimed that his paper is the first reported case of a lumbar disc herniation with migration to the posterior aspect of the caudal $\mathrm{sac}^{12)}$. Dorsally migrated lumbar herniated nucleus pulposus is very rare entity but not uncommon and are reported as isolated case report and series. To our knowledge only less than 65 dorsally migrated discs has been described in literature till date ${ }^{4,7,9)}$.

Dorsally migrated disc herniation poses challenges from diagnosis to treatment methods ${ }^{3,10)}$ because it mimics with many other problems like epidural haematoma ${ }^{18)}$, tumor $^{1,5,7,8)}$, facetal cyst $^{17,20)}$, infection ${ }^{18)}$. Diagnosis is made on the basis of clinical examination, imaging, labarotary tests as an exclusion. MRI is choice of imaging ${ }^{2,6,14)}$.
Treatment modality mostly being practiced for dorsally migrated lumbar disc at present is open surgey ${ }^{1-3,5,6,10,12-14,16,17,19,20)}$. There is single case report of endoscopic removal11 of dorsally migrated lumbar disc but with laminotomy and ligamentum flavum excision and it is not percutaneous full endoscopic technique.

We treated this condition of dorsally migrated lumbar disc in presence of subtle instability in 60 years old man presented with subacute onset ( 2 weeks) of low back pain and right leg radiating pain with weakness of right great toe dorsiflexion by a full endoscopic technique called Percutaneous Full Endoscopic Ligamentum Flavum Splitting Interlaminar Approach sparing ligamentum flavum with successful outcome.

This technique not only addresses symptomatic pathology caused by dorsally migrated HNP but also simultaneously preserves motion segments. We want to share our case with this case report. 


\section{CASE REPORT}

A 60 years old otherwise healthy gentle man presented after 2 weeks of gradual onset of symptoms with complaint of low back pain (LBP) associated with right leg pain and weakness of right great toe dorsiflexion without any significant history of trauma. He had no medical co morbidity He was thoroughly examined and investigated. His LBP and leg pain in Visual Analogue Scale (VAS) was 5/10 and 8/10 respectively. He had weakness of right toe dorsiflexion with grade $3 / 5$ in Medical Research Council (MRC) grade. SLRT was 45 degrees on right side, 80 degrees on left side. $X$-rays revealed subtle instability in L4-5 in flexion and extension as subtle anterior wedging (Fig. 1A, 1B, 1C). CT revealed huge disc posteriorly (Fig. 1D,
1E). MRI showed a huge mass dorsal to dura at L4-5 level and it was compressing the dura (Fig. 1F, 1G). Working diagnosis of dorsally migrated disc with subtle instability was made on the basis of clinical presentation, imaging findings and laboratory tests. He was treated with Percutaneous Full Endoscopic Ligamentum Flavum Splitting Interlaminar Approach sparing ligamentum flavum (Fig. 2). A huge disc was removed. Final diagnosis of dorsally migrated disc was made with retrieval of disc material by endoscope. His pain resolved immediately after surgery. Weakness of right great toe also resolved gradually in 2 months. Postoperative X-ray showed no further instability (Fig. 3A,3B). Postoperative MRI revealed complete removal of disc with resolution of cord compression (Fig. 3C, 3D). No complication was noted related to this technique.
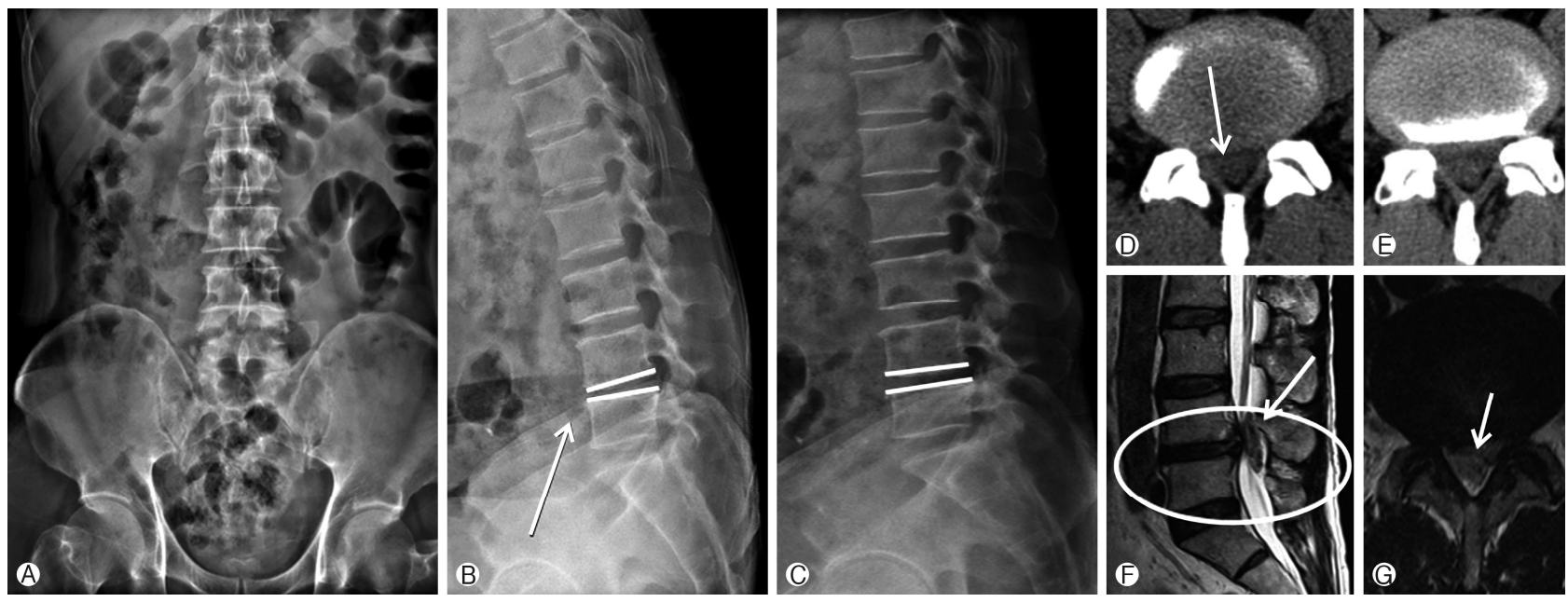

Fig. 1. Preoperative imaging. Preoperative X-ray of LS spine with Pelvis AP (A) and Dynamic LS spine lateral views in Flexion and Extension (B) and (C) showing subtle anterior wedging (arrow). Preoperative axial CT of L4-5 segment (D) and (E)) showing huge disc herniation in spinal canal epidural space (arrow). Preoperative MRI sagittal $(F$ and axial (G) showing huge dorsally migrated disc (encircled in sagittal film) with significant canal compromise (arrow in axial film).
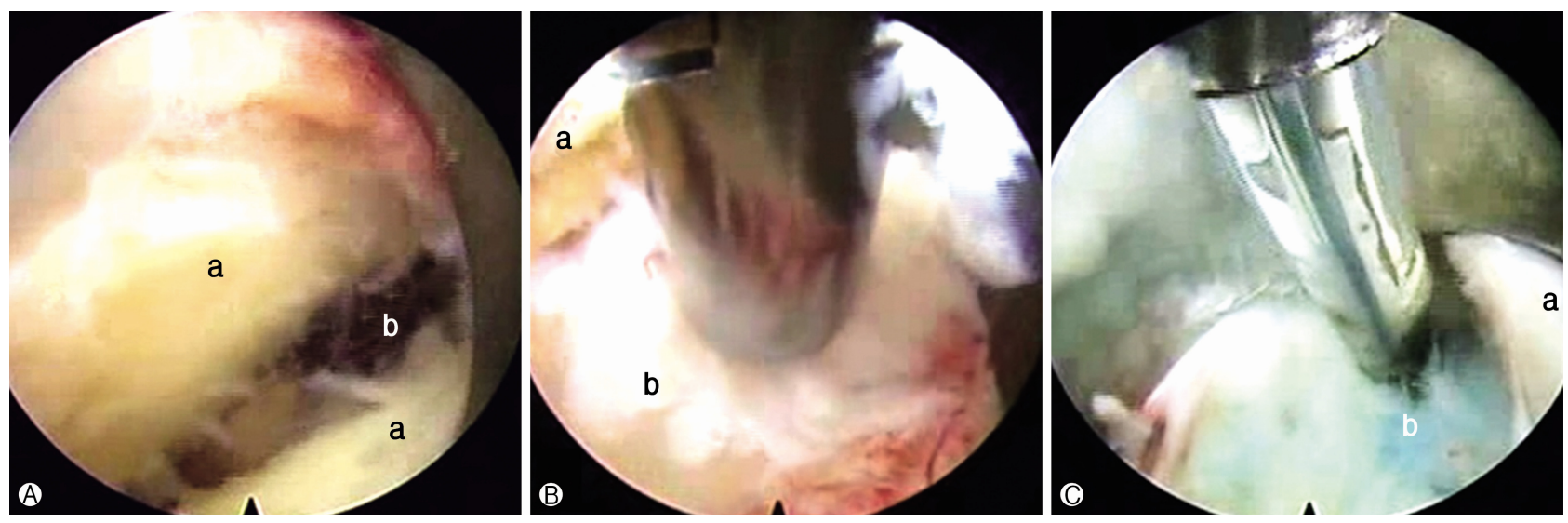

Fig. 2. Intraoperative photograph of endoscopic view of disc fragment removal. (A) Limgamentum flavum splitting: a. ligamentum flavum, b. epidural space, (B) Removal of dorsally migrated HNP: a. ligamentum flavum, b. dorsally migrated HNP, (C) Confirmation and sealing of torn annulus fibrosus: a. ligamentum flavum, b. torn annulus fibrosus. 

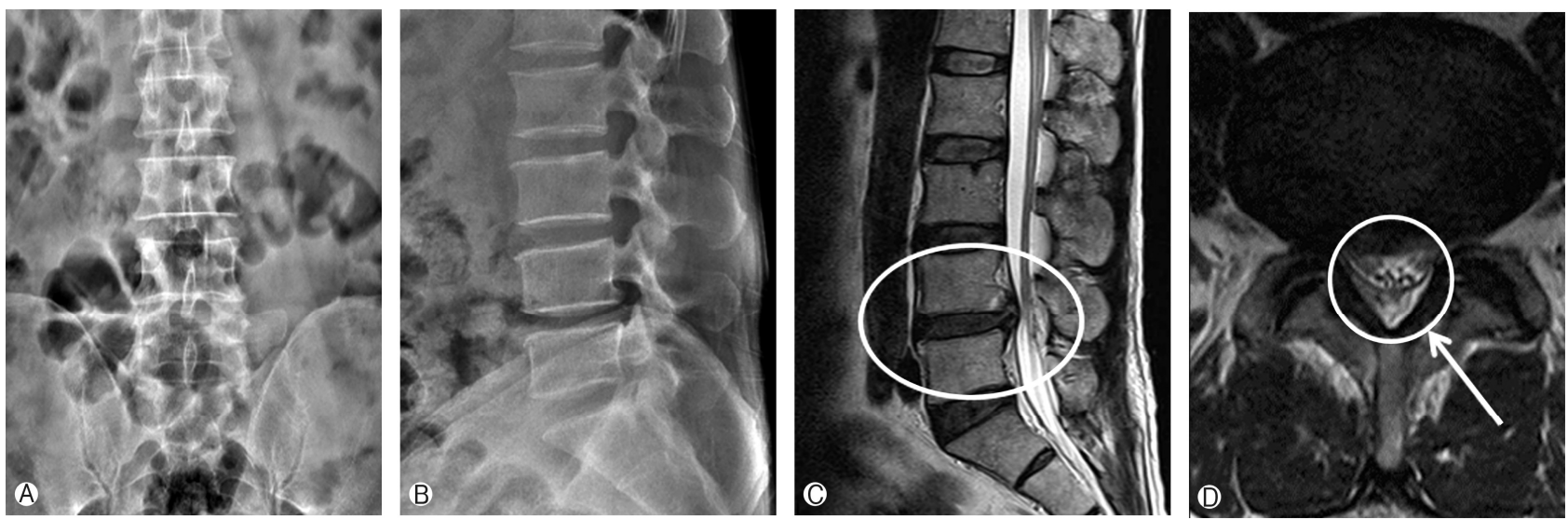

Fig. 3. Postoperative imaging. (A), (B): Post operative X-ray LS spine with Pelvis AP (A) and LS spine lateral view (B). (C), (D): Postoperative MRI showing complete removal of dorsally migrated disc (Spinal canal free now, encircled) and preservation of ligamentum flavum and lamina (arrow).

\section{DISCUSSION}

\section{Description of Surgical Technique}

Patient was placed over Wilson frame with proper padding after epidural anaesthesia. Drapping was done then.Discography was then performed with indigo carmine mixed with radiopaque dye using a transforaminal approach at $L 4-5$ to delineate pathological disc. The standard endoscopic interlaminar discectomy approach as drescribed in literature at L4-5 level was followed. But it was slightly modified for ligamentum flavum management. After insertion of endoscope, obstructing muscle and fat were removed to visualize the ligamentum flavum. Vertical splitting of ligamentum flavum was then performed using a dissector. The bevel of a working channel was inserted into the splitted ligamentum flavum and rotated to widen the opening, while simultaneously entering into the epidural space (Fig. 2). Dorsally migrated disc was then removed. Annular sealing was done following herniation path to annulus.

Lumbar herniated nucleus pulposus (HNP) usually migrates to superior, inferior or lateral in anterior epidural space. But very uncommonly it migrates to posterior epidural space. Posterior migration of herniated nucleus pulposus is uncommon because there are natural anatomic barriers between anterior and posterior epidural space ${ }^{15,19)}$.

Treatment of dorsally migrated HNP described so far commonly in present literature is removal by open technique through hemi or complete laminectomy ${ }^{1-3,5,6,10,12-14,16,17,19,20)}$. In one paper there is use of microsurgical technique16 and there is one another paper where endoscope ${ }^{11)}$ was used but with sacrifice of ligamentum flavum and part of lamina and this is not a full endoscopic technique because it has not used irrigation system.

This case is presented here because Percutaneous full endoscopic procedure is a minimally invasive anatomic approach with visualization of important structure with magnification. Usually in conventional approach ligament flavum and part of lamina are sacrificed. But ligamentum flavum and lamina should be preserved as far as possible because these are motion preserving stabilizing structure of spine. Importance of our technique weighs more when there is subtle instability in the motion segment.

Removal of dorsally migrated HNP sparing ligamentum flavum (ligament flavum splitting) by full endoscopic technique is feasible and safe. This techniques not only addresses symptomatic pathology caused by dorsally migrated HNP but also simultaneously preserves motion segments and provides added benefits of minimal invasive spine surgery. Moreover our patient recovered well after this endoscopic procedure completely with no complication.

To our knowledge this is probably a first case of dorsally migrated lumbar disc in the world which has been treated with percutaneous full endoscopic technique and preservation of ligamentum flavum. We believe that future of removal of dorsally migrated lumbar disc herniation is full percutaneous endoscopic in term of benefits of minimal invasive spine surgery and early recovery.

Previous Presentation in Conference: Presented in Asia Spine and KNS conference 2016.

IRB approval: Received from Nanoori Hospital IRB board.

\section{ACKNOWLEDGEMENT}

We would like to acknowledge scientific team members Ms. JaeEun Park and Ms Sol Lee for providing assistance in acquiring full text articles and managing digital works.

\section{REFERENCES}

1. Ajayi O, Shoakazemi A, Tubbs RS, Moisi M, Rostad S, Newell DW: Atypical Presentation of a Sequestered Posterolateral Disc Fragment. Cureus 8(2):e502, 2016; doi:10.7759/cureus.502. 
2. Babayev R, Ekşi EE, Kazımov A, Ekşi MŞ: A common pathology in an uncommon location:posterior migrated epidural disc herniation. Spine J 16(9):e583-584, 2016

3. BonarotiEA, Welch WC. Posterior epidural migration of an extruded lumbar disc fragment causing cauda equina syndrome. Clinical and magnetic resonance imaging evaluation. Spine (Phila Pa 1976) 23(3):378-381, 1998

4. Bouya SM, Djoubairou BO, Okacha N, Gazzaz M, Mostarchid BE: Posterior epidural migration of lumbar intervertebral fragment: case report. Pan Afr Med J 21:80, 2015; doi:10.11604/ pamj.2015.21.80.6993

5. Carvi y Nievas MN, Hoellerhage HG: Unusual sequestered disc fragments simulating spinal tumors and other space occupying lesions. Clinical article. J Neurosurg Spine 11(1):428, 2009

6. Chen CY, Chuang YL, Yao MS, Chiu WT, Chen CL, Chan WP: Posterior epidural migration of a sequestrated lumbar disk fragment: MR imaging findings. AJNR Am J Neuroradiol 27(7): 1592-1594, 2006

7. Diyora BD, Giri S, Giri D, Kotecha N, Patil S: An unusual case of dorsally sequestered disk mimicking tumour with cauda equine syndrome. J Spinal Surg 3(1):15-17, 2016

8. Ekşi MS, Yener U, Akakin A, Akakin D, Konya D. Posterior epidural disc herniation at L3-4 micmicking a spinal tumor: a case report. J Neurosurg Sci 54(2):71-76, 2010

9. Haddadi K, Qazvini HRG: Posterior Epidural Migration of a Sequestrated Lumbar Disk Fragment Causing Cauda Equina Syndrome in an Old Patient: ACase Report. Clin Med Insights Case Rep 9:39-41, 2016; doi:10.4137/CCRep.S39139

10. Kim JS, Lee SH, Arbatti NJ: Dorsal Extradural Lumbar Disc Herniation Causing Cauda Equina Syndrome: A Case Report and Review of Literature. J Korean Neurosurg Soc 47:217-220, 2010

11. Koga S, Sairyo K, Kon T, Shibuya I, Kanamori Y, Kosugi T,
Konno R, Arai T, Dezawa A: Endoscopic removal of herniated nucleus pulposus migrated dorsally to the dural sac. Asian J Endosc Surg 4(1):36-39, 2011

12. Lichtor T: Posterior epidural migration of extruded lumbar disc. Surg Neurol 32:311-312, 1989

13. Lombardi V: Lumbar spinal block by posterior rotation of annulus fibrosus. Case report. J Neurosurg 39:642-647, 1973

14. Neugroschl C, Kehrli P, Gigaud M, Ragragui O, Maitrot D, Manelfe C, Dietemann JL: Posterior extradural migration of extruded thoracic and lumbar disc fragments: role of MRI. Neuroradiology 41(9):630-635, 1999

15. Schellinger D, Manz HJ, Vidic B, Patronas NJ, Deveikis JP, Muraki AS, Abdullah DC: Disk fragment migration. Radiology 175(3):831-836, 1990

16. Sengoz A, Kotil K, Tasdemiroglu E: Posterior epidural migration of herniated lumbar disc fragment. J Neurosurg Spine 14(3): 31-37, 2011

17. Taoka Y, Naruo M, Koyanagi E, Urakado M, Nogami T: Posterior extradural disc fragmenta case report. Acta Orthop Scand 67(5):510-512, 1996

18. Teufack SG, Singh H, Harrop J, Ratliff J: Dorsal Epidural Intervertebral Disk Herniation With Atypical Radiographic Findings: Case Report and Literature Review. J Spinal Cord Med 33(3):268-271, 2010

19. Wiltse LL, Fonseca AS, Amster J, Dimartino P, Ravessoud FA: Relationship of the dura, Hofmann's ligaments, Batson's plexus, and a fibrovascular membrane lying on the posterior surface of the vertebral bodies and attaching to the deep layer of the posterior longitudinal ligament. An anatomical, radiologic, and clinical study. Spine (Phila Pa 1976) 18(8):1030-1043, 1993

20. Yoo YS, Ju CL, Kim SK, Kim DM: Posterior Epidural Migration of an Extruded Lumbar Disc Mimicking a Facet Cyst: A Case Report. Korean J Spine 12(1):12-14, 2015 